\title{
LIVRO DIDÁTICO: FERRAMENTA DE REPRESENTAÇÃO
} CULTURAL

\author{
Textbook: a Tool of Cultural Representation
}

\section{Iara Maria BRUZ, Celin e UNINTER ${ }^{1}$}

RESUMO: Este artigo traz uma análise de um livro didático utilizado no Celin - Centro de Línguas e Interculturalidade da UFPR - Universidade Federal do Paraná - sob o viés das forças centrífugas e centrípetas de linguagem propostas por BAKHTIN (2002, 2003, 2009). Partindo do pressuposto de que linguagem e cultura são conceitos indissociáveis e que as culturas não são isoladas e estão em contato com outras culturas, acredita-se que a sala de aula de línguas estrangeiras pode trazer essa realidade para o aluno. Neste contexto, o livro didático é uma das ferramentas que os professores utilizam para trazerem a cultura alvo para seus alunos. Além dos pressupostos de BAKHTIN (2002, 2003, 2009), foram utilizados os conceitos de cultura pensados por EAGLETON (2005) e BHABHA (1998) para dar embasamento teórico ao estudo. Esta análise pretende mostrar uma maneira como as personagens dos livros didáticos representam a cultura alvo através da análise de suas falas com o auxílio das concepções de linguagem bakhtinianas.

PALAVRAS-CHAVE: Livro Didático; Interculturalidade; Ensino de LE.

ABSTRACT: This article brings the analysis of a textbook used at Celin - Centro de Línguas e Interculturalidade at UFPR - Federal University of Paraná - under the bias of the languages centrifugal and centripetal forces proposed by BAKHTIN (2002, 2003, 2009). Assuming that language and culture are inseparable, and there is no culture which is isolated but rather in contact with other cultures, it is believed that in the foreign language classroom this reality can be shown to the student. In this context, the textbook is one of the tools teachers use, and it also brings the target culture to learners. In addition to BAKHTIN (2002, 2003, 2009)'s assumptions, the culture concepts culture from EAGLETON (2005) and BHABHA (1998) were used to provide theoretical support to the analysis. This analysis intends to show a way characters from textbooks represent the target culture through an analysis of their words with the support of the bakhtinian concepts of language.

KEY WORDS: Textbooks; Interculturality; FL teaching.

\section{INTRODUÇÃO}

O Celin - Centro de Línguas e Interculturalidade, vinculado à Universidade Federal do Paraná - é uma instituição que atende tanto à comunidade interna quanto à

\footnotetext{
1 Professora de Língua Inglesa no Celin - UFPR e na UNINTER. Mestre em Educação pela UFPR. .
} 
externa à UFPR, ofertando cursos de línguas e culturas diversas. Além de oferecer oportunidade aos alunos do curso de Letras para a prática docente, é também um espaço que incentiva os professores a pensarem e repensarem suas práticas em sala de aula, incluindo o uso dos Livros Didáticos (doravante LDs) ${ }^{2}$.

Durante meu percurso como professora de inglês, pude me certificar de que os LDs constituem um objeto de estudo relevante, já que são ferramentas amplamente utilizadas nas salas de aulas de línguas estrangeiras. No que concerne os LDs de ensino de língua inglesa encontramos algumas peculiaridades. Na sala de aula, onde esses LDs são usados, ocorre o encontro de diversas (sub)culturas: a do professor com a dos alunos, as culturas e subculturas dos diferentes tipos de grupos de alunos, etc. Quando se trata do ensino de uma língua estrangeira, parece relevante que o professor esteja consciente de que estará presente em sua sala de aula, além da cultura dos alunos e da sua própria, a cultura da língua-alvo. Como a língua-alvo pode ser a língua de diferentes países, o professor poderá dialogar com diversas vertentes culturais. Esse é mais um confronto ${ }^{3}$ que se coloca tanto para os docentes quanto para os alunos.

No caso desta pesquisa, de cunho qualitativo, foi realizada uma análise de conteúdo de um exemplar de LD de língua inglesa, o livro New American Inside Out Elementary (JONES, Vaughan \& KAY, Sue, 2009), utilizado nos níveis de básico 3 e 4 do curso oferecido pelo Celin, correspondentes aos terceiro e quarto semestres. Em síntese, pretendo verificar que possíveis representações socioculturais podem estar sendo transmitidas para os usuários desse LD (alunos e professores).

Além disso, acredito que a língua não pode ser separada da cultura e por isso quando se aprende uma língua estrangeira, estamos também adquirindo conhecimentos sobre a cultura alvo. E como o LD é uma das ferramentas utilizadas pelos professores de língua estrangeira e pelos seus alunos, sendo as aulas e conteúdos baseados nesses instrumentos, é relevante que averiguemos se o LD também é uma ferramenta para o aluno chegar à língua alvo, uma vez que as falas e a presença de personagens nos LD são meios para que isso possa acontecer.

\footnotetext{
${ }^{2}$ Este trabalho é um recorte da minha dissertação de Mestrado em Educação pela UFPR defendida em abril de 2012.

${ }^{3}$ Quando o termo confronto é aqui utilizado, não se espera uma conotação negativa; pelo contrário. É através do confronto de ideias e opiniões que novas situações são formadas. Assim o contato com o diferente, que em um primeiro momento pode resultar em estranhamento, pode gerar uma nova forma de pensamento.
} 
Como fundamentação teórica, foram feitas reflexões sobre visões de cultura que embasam as escolhas feitas por LDs na apresentação de seus conteúdos. Para fazer essa reflexão, me aterei principalmente às contribuições de dois autores: Terry Eagleton (2005) e Homi Bhabha (1998). Esses autores nos levam a refletir sobre a construção de uma cultura que está em constante mudança e não é fixa, nem isolada. Em seguida, a concepção de cultura que norteou este trabalho é apresentada.

Também é essencial indicar que a concepção de linguagem que serve de base para este estudo é a do Círculo de Bakhtin ${ }^{4}$, pois esta concepção vai ao encontro da concepção de cultura que orienta a pesquisa. Nesta concepção, a linguagem é entendida como inserida na realidade dos indivíduos que usam a língua para se comunicar. A abstração de uma língua, portanto, só ocorre para determinados fins e não seria a concepção mais adequada para a presente pesquisa.

\section{INTERCULTURALIDADE E ENSINO}

Terry Eagleton (2005) indica a natureza das discussões que envolvem o conceito de cultura e destaca a importância desta da seguinte forma:

[n]ós não nascemos como seres culturais, nem como seres naturais autossuficientes, mas como criaturas cuja natureza física indefesa é tal que a cultura é uma necessidade se for para que sobrevivamos. A cultura é o "suplemento" que tampa um buraco no cerne de nossa natureza e nossas necessidades materiais são então remodeladas em seus termos (ibid., p. 143).

Os sujeitos envolvidos na construção dos LDs, nosso objeto de estudo, utilizam-se de uma concepção de cultura para a criação de seus personagens, cenários e escolha das imagens. Além de uma concepção de cultura, os autores também colocam sua concepção de linguagem. Ambas podem ser representadas por apenas uma visão, ou representativas de uma visão plural.

\footnotetext{
${ }^{4}$ Segundo Faraco (2009), o termo Círculo de Bakhtin é usado para se referir aos escritos de diferentes autores, de "diversas formações, interesses intelectuais e atuações profissionais" (FARACO, 2009, p. 13), incluindo Mikhail M. Bakhtin e Valentin N. Voloshínov que mais nos interessam no presente estudo. A denominação Círculo de Bakhtin "foi-lhes atribuída a posteriori (...). A escolha do nome de Bakhtin, neste caso, é plenamente justificável, tendo-se em conta que, dentre todos, foi ele quem produziu, sem dúvida, a obra de maior envergadura" (FARACO, 2009, p. 13).
} 
Se as diferenças entre as culturas são negadas, a outra cultura será vista como homogênea, assim como os indivíduos que fazem parte dela. Por isso: "[n]este contexto, é emblemático os que têm tal atitude não enxergarem os indivíduos, porém apenas grupos" (JANZEN, 2008, p. 26). Assim, o que é diferente de certa cultura também lhe será, provavelmente, estranho. Isso é compreensível se considerarmos que pensamos nossa cultura através das nossas experiências:

Para uma pessoa, seu próprio modo de vida é simplesmente humano; são os outros que são étnicos, idiossincráticos, culturalmente peculiares. De maneira análoga, seus próprios pontos de vista são razoáveis, ao passo que os dos outros são extremistas (EAGLETON, 2005, p. 43).

Já que nosso modo de vida é a norma para nós, é através desse modo de vida que visualizamos o outro. São as próprias experiências que produzem as perspectivas que as pessoas têm do mundo à sua volta. Em considerando que a visão tradicional de cultura é percebida como homogênea, podemos considerá-la, em tese, como uma visão fixa e imutável de cultura. Talvez, por isso, essa visão ainda se encontre tão presente nas escolas e nos LDs adotados por elas, uma vez que essa percepção cultural não se modifica.

Terry Eagleton (2005), explica que o estereótipo se constrói a partir dessas repetições: "sempre as mesmas histórias (...) têm de ser contadas (compulsivamente) repetidamente, e são gratificantes e aterrorizantes de modo diferente a cada vez." (ibid., p. 120, grifos do autor). Um exemplo disso é o irlandês apresentado como estúpido; ou para nós brasileiros, o português que não é muito inteligente; ou para os americanos os latinos que são todos mexicanos. Ou seja, para o estereótipo ser construído, é preciso que essas histórias se repitam.

Concordamos com Eagleton (2005) quando ele indica a cultura como modo de vida. A cultura pode trazer pensamentos e ações totalmente heterogêneos convivendo lado a lado, o que vai de encontro à visão de cultura que é percebida como homogênea. Eagleton (2005) assinala ainda que "todas as culturas estão envolvidas umas com as outras; nenhuma é isolada e pura, todas são híbridas, heterogêneas, extraordinariamente diferenciadas e não monolíticas" (EAGLETON, 2005, p. 28).

Quando duas culturas (ou mais) entram em contato, há o surgimento de uma terceira alternativa. Segundo Homi Bhabha (1998), não há mais o mundo em termos 
binários e sim o surgimento de um mundo híbrido. Quando este mundo surge, as diferenças das culturas anteriores não podem mais ser observadas, pois não estão mais lá. Esse terceiro espaço que surge não mostra claramente as características das culturas que o formaram, oferecendo outras opções em seu lugar. Não se pode definir claramente onde acaba uma cultura para começar a outra, ou seja, as fronteiras não são visíveis. Existe o surgimento de um "Terceiro Espaço", um mundo híbrido, que seria um local de negociação dessas duas culturas anteriores.

Pode-se concluir que o surgimento de um mundo híbrido ocorre de uma forma mais intensa hoje nos países que recebem imigrantes. Estes tendem a não abandonar a cultura de seu país de origem e muito menos incorporar a cultura da nova morada incondicionalmente, mas tendem a formar uma nova alternativa, criando uma cultura híbrida. Além disso, as novas tecnologias trouxeram para o mundo novas possibilidades, o que afeta o contato entre diferentes culturas também.

Levando em consideração essas reflexões iniciais sobre visões de cultura, abro parênteses para indicar que opto - para a orientação de viés teórico-prático do trabalho e para análise posterior dos LDs - por uma perspectiva de cultura mutável e heterogênea, que está em constante contato com outras culturas.

Essa concepção de encontro cultural que pressupõe o rearranjo constante na construção de sentidos dos interlocutores de diversas culturas também pode ser encontrada na perspectiva de interculturalidade de Tedeschi (2008). Nesse sentido, vale destacar que acredito, assim como o autor, que:

(...) numa perspectiva intercultural não basta reconhecer a diferença, é preciso estabelecer uma relação, a inter-relação entre pessoas de culturas diferentes para justamente permitir um entendimento recíproco, de tal forma que essa relação implique um desafio à reelaboração de cada um (TEDESCHI, 2008, p. 15).

A concepção de cultura que considero para este estudo é uma concepção que vai de acordo com os autores já mencionados: Eagleton (2005), Bhabha (1998) e Janzen (2005). Acredito em uma concepção de cultura que não seja monolítica, ou seja, que não a conceba como uma verdade absoluta. Concordo com Almeida (2011) quando a pesquisadora argumenta que: "percebemos as diferenças, refletimos sobre elas, podemos ou não modificar conscientemente nossa visão a partir da visão do outro, cientes de que as diferenças vão sempre existir" (ALMEIDA, 2011, p. 26). 
Pleiteio, portanto, para esta pesquisa uma concepção de cultura plural, baseando-me no que foi discutido sobre os escritos de Bhabha (1998) e Eagleton (2005). Assim, pensamos a cultura do outro de forma mutável e heterogênea, concebendo um constante contato intercultural. Vale destacar também que essa perspectiva de interculturalidade está calcada, na presente pesquisa, em uma visão multicultural, ou seja, uma visão em que os indivíduos participam de diversas culturas, seja na sua comunidade, escola ou trabalho, nação, etc.

Outra contribuição de Almeida (2011), sintetiza a perspectiva do ambiente de sala de aula que defendo:

[a] sala de aula é vista assim como um local onde não há verdades préestabelecidas, saberes prontos e imutáveis, um local onde o conhecimento é construído por professores e alunos em conjunto, e onde há sempre lugar para constantes transformações. Construir, desconstruir, reconstruir de formas diferentes - um lugar em constante ebulição (ibid., p. 41).

A partir dos elementos constituintes do arcabouço teórico bakhtiniano ${ }^{5}$ e também dos pressupostos que orientam a visão de cultura que compartilho, irei refletir sobre o LD. Segundo o Círculo de Bakhtin (2003, 2009), toda palavra ou expressão quando inseridos em um determinado contexto se tornam enunciados e possuem fins comunicativos. Concordo que estruturas gramaticais só passam a ser enunciados quando são utilizados para esses fins.

Entendo que os enunciados estão inseridos em um contexto, e são orientados por uma intenção. Cada vez que um enunciado é proferido, ele o é em um contexto específico, e o enunciador escolherá as estruturas e o léxico para aquela situação. A intenção sempre está presente na comunicação, de modo que toda vez que um indivíduo quer comunicar suas ideias, pensa como quer que elas cheguem até seu interlocutor.

Outros elementos do universo epistemológico bakhtiniano - presentes na base da discussão associada aos estudos discursivos - são as forças centrípetas e as forças centrífugas (cf. BAKHTIN (2002)). A primeira seria o discurso dominante, e a segunda os contradiscursos. As forças centrípetas são:

(...) aquelas da unificação e da centralização das ideologias verbais. A categoria da linguagem única é uma expressão teórica dos processos históricos

\footnotetext{
${ }^{5}$ Usamos o termo bakhtiniano nos mesmos moldes que aceitamos a terminologia "Círculo de Bakhtin" (cf. nota 2$)$.
} 
da unificação e da centralização linguística, das forças centrípetas da língua. A língua única não é dada, mas, em essência, estabelecida em cada momento da sua vida, ela se opõe ao discurso diversificado (BAKHTIN, 2002, p. 81, grifo do autor).

Por outro lado, as forças centrífugas agem para descentralizar o discurso dominante. Assim:

(...) ao lado das forças centrípetas caminha o trabalho contínuo das forças centrífugas da língua, ao lado da centralização verbo-ideológica e da união caminham ininterruptos os processos de descentralização e desunificação (ibid., p. 82).

Assim, e como Bakhtin, acredito que as duas forças mencionadas estão presentes na sala de aula. Afinal, "[c]ada enunciação concreta do sujeito do discurso constitui o ponto de aplicação seja das forças centrípetas, como das centrífugas." (ibid., p. 82). Porém, nem sempre é dada a elas a atenção suficiente para que os alunos percebam-nas. Apenas através da representação dessas duas forças, os alunos podem ter acesso às variantes socioculturais e lingüísticas que os auxiliam a dizer o que desejam, que os ajudam a dizer suas verdades ou mentiras, suas opiniões, para se expressarem sobre o que concordam e discordam, se colocarem como agentes em sua aprendizagem da língua inglesa.

$\mathrm{Na}$ aula de língua estrangeira, espera-se que o professor ajude o aluno a manter-se numa posição em que possa utilizar os conteúdos aprendidos em sala para comunicar-se em situações reais. Ou seja, exercícios esquemáticos que objetivam apenas a reprodução de estruturas gramaticais já prontas poderiam, dentro dessa perspectiva, ser evitados, uma vez que este tipo de exercícios tornaria mais difícil para os alunos criarem um vínculo com o que estão dizendo em sala de aula e formularem sentidos na produção dos enunciados, para então fazerem uma ponte entre a sala de aula e suas realidades. Pois, segundo Bakhtin, "a língua passa a integrar a vida através de enunciados concretos (que realizam); é igualmente através de enunciados concretos que a vida entra na língua.” (2003, pág. 265). Em vez do conteúdo ser apresentado dessa forma (com predominância de estruturas gramaticais), os LDs poderiam facilitar as práticas socioverbais dos alunos apresentando o conteúdo contextualizado em situações que possam ser relacionados mais facilmente à realidade dos alunos. 


\section{LIVRO DIDÁTICO: UMA REFLEXÃO}

Muitos pesquisadores (tais como BATISTA, 2002; CORACINI, 2011; GRIGOLETTO, 2011, etc.) têm como foco de pesquisa o LD. Antes de prosseguir para a questão atual dos seus usos, farei um breve histórico dos LDs, com o propósito de refletir sobre a mutabilidade destes ao longo dos anos, e compreende desde seu formato até sua comercialização.

O LD exerce um papel de grande relevância para o ambiente escolar, como relata o pesquisador Antônio Batista (2002):

[o] livro didático desenvolve um papel importante no quadro mais amplo da cultura brasileira, das práticas de letramento e do campo da produção editorial e compreende, consequentemente, diferentes dimensões de nossa cultura, de suas relações com a escrita e com o letramento, assim como processos sociais, culturais e econômicos de diferentes facetas da produção editorial brasileira significam também compreender o livro escolar brasileiro (BATISTA in ABREU, 2002, p. 534).

Vale ressaltar que não vejo o objeto deste estudo como se ele sempre tivesse existido na forma como o conhecemos, nem acredito que sempre terá esse formato. Como nos lembra Batista (2002), o LD "é, por fim, um objeto multifacetado, que possui diferentes dimensões, relacionadas às condições com base nas quais é construído" (ibid., p. 566). O LD faz parte da história da escola, e fez parte da vida de quase todos que passaram por essa instituição. Talvez, por isso, muitas vezes ele seja aceito sem ser questionado.

Hoje o LD é tratado frequentemente como uma mercadoria de consumo, como indica Batista (2002):

(...) os impressos didáticos ${ }^{6}$ são uma mercadoria e (...), consequentemente, sua produção, circulação e utilização são regidas por uma infra-estrutura organizada em torno das possibilidades materiais, técnicas, institucionais e comerciais de uma determinada sociedade, num determinado momento de sua história (ibid., p. 554).

\footnotetext{
${ }^{6} \mathrm{O}$ autor se refere a alguns dos materiais utilizados em sala de aula como impressos. Os "impressos" incluem qualquer material impresso que professores utilizam, mas não necessariamente em formato de livros. Dentre esses materiais está incluso o LD.
} 
Segundo Batista (2002), o LD é desprestigiado, assim como os pesquisadores que se ocupam desse tema. Uma pesquisa realizada pela Folha de S. Paulo e mencionada pelo autor, porém, apontou que, em 1997, 70\% dos livros produzidos no país se destinavam ao ensino (ibid., p. 532). Mais atualmente, em 2007, a revista Época publicou uma reportagem intitulada "Maior segmental do mercado editorial é o de livros didáticos", na qual destaca a importância comercial que a indústria de LD criou no Brasil. Embora, alguns analistas - como Batista (2002) - indiquem uma certa falta de prestígio dos LDs, ele é um bem de consumo, presente nas escolas em todo o país, e movimenta milhões de reais com suas vendas (ibid., 2002).

Vale ressaltar que o LD é visto como "autoridade" pelos professores, como um “modelo-padrão". Segundo Grigoletto (2011), "criando-se o efeito de um discurso cuja verdade “já está lá', na sua concepção.” (Ibid., p. 68). A autora destaca que o docente acredita que o LD traz modelos que podem ser seguidos pelos seus alunos, pois esses exemplos foram legitimados pelos autores (é a certeza de que os autores dos materiais possuem conhecimentos que são legitimados e conhecem melhor o conteúdo a ser ensinada do que os professores, usuários desses livros). Além disso, em algumas situações, o LD acaba sendo “a única fonte de acesso ao 'saber institucionalizado' de que dispõem professores e alunos" (CARMAGNANI, 2011, p. 127).

Infelizmente, na escola, o LD é visto frequentemente "como um texto fechado, no qual seus sentidos já estão estabelecidos (pelo autor), para ser apenas reconhecido e consumido pelos seus usuários (professor e aluno)" (GRIGOLETTO, 2011, p. 67). Nesta perspectiva, o conteúdo não é questionado, nem pelos alunos, nem pelos professores, e nem pela escola em geral (coordenação, diretoria). Mesmo em lugares em que os professores têm acesso a diversos outros materiais complementares, o que deveria ser uma ferramenta de apoio acaba se transformando em único recurso.

Os conteúdos apresentados pelos LDs são vistos como a verdade (única e inquestionável). Segundo Grigoletto (2011), esse discurso de verdade possui algumas características. Ele tem um "caráter homogeneizante", que considera os alunos como um bloco de indivíduos iguais uns aos outros, independentemente do local onde o LD é usado. Também se encontra nos LDs a "repetição" dos exercícios, que leva os alunos a uniformizarem suas reações diante das atividades ali propostas. E, por fim, a apresentação dos conteúdos é construída de tal forma que pode indicá-los como naturais, "criando-se o 
efeito de um discurso cuja verdade “já está lá', na sua concepção” (GRIGOLETTO in CORACINI, 2011, p. 68).

\section{ANÁLISE DE UM LIVRO DIDÁTICO ADOTADO NO CELIN}

Como já foi mencionado na introdução, o livro adotado nos terceiro e quarto semestres do Celin, em 2012, é o New American Inside Out Elementary (2009) (NAIO) e este foi o instrumento analisado neste artigo ${ }^{7}$. O livro contém 16 unidades e todas foram analisadas. Porém, procuraram-se exemplos de personagens que possuíam algum indício de serem estrangeiros, para verificarmos como uma cultura vista como não nativa está representada neste livro. Tarefa árdua, já que os personagens são descontextualizados. Por uma questão de espaço, destes exemplos, selecionamos apenas quatro para o presente trabalho.

Sabemos, já pelo título do livro, que o pano de fundo para as ações das personagens e para mostrar o conteúdo neste LD é os Estados Unidos. Uma das maneiras que os LDs representam as culturas em suas páginas é através da apresentação de personagens; e estes personagens podem ser porta vozes dos indivíduos que vivem em uma dada cultura. Além disso, os LDs atualmente fazem uso de imagens e fotografias para que o aluno possa visualizar a situação sendo explorada.

Um primeiro exemplo é encontrado na primeira unidade intitulada "Aeroporto", (JONES, Vaughan \& KAY, Sue 2009b, p. 4) encontramos duas personagens em um avião. Uma das personagens é uma mulher brasileira, a outra é um homem da cultura-alvo9. O vôo no qual os dois se encontram tem como destino Nova Iorque (figura 1). Acontece uma pequena interação entre eles, em que ocorre a troca de informações tais como nome e local de origem.

\footnotetext{
${ }^{7}$ Este é um recorte da dissertação intitulada Análise de Livros Didáticos de Língua Inglesa sob o viés da Interculturalidade. (BRUZ, 2012). Foi escolhida para este artigo a análise resumida do livro em questão. ${ }^{8}$ Airport.

${ }^{9}$ Para fins didáticos, quando me refiro à cultura-alvo, estou me referindo à cultura estadunidense.
} 


\section{Listening}

1 . 1.02 Read and listen to the conversation. Answer the questions. a) What's his name? b) What's her name?

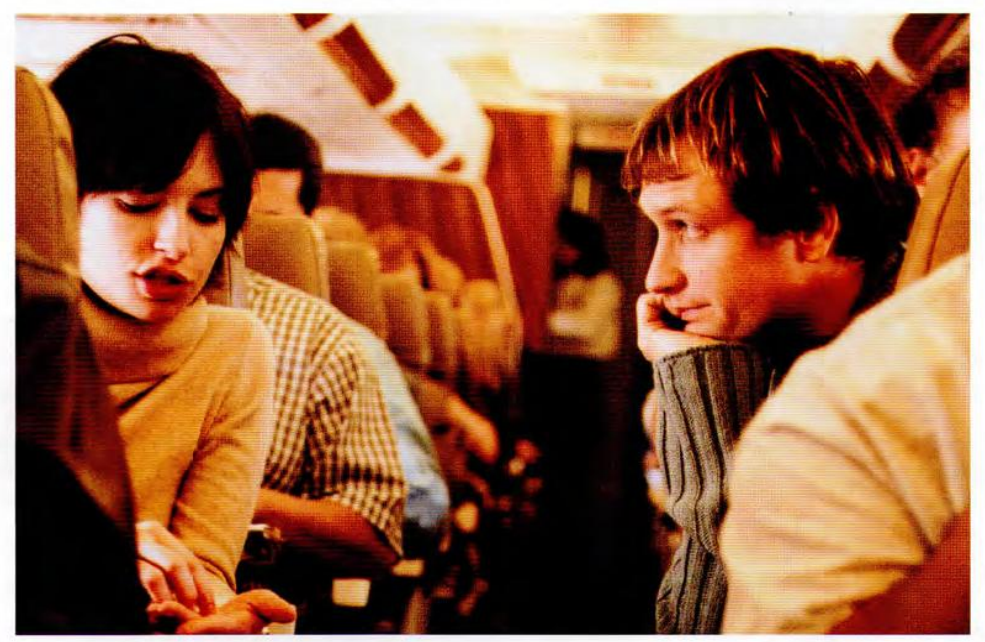

Figura 1
A: Oi, eu sou Mike. Qual seu nome?
B: Oh, olá. Sou Elena.
A: Você é americana?
B: Não sou. Sou brasileira. Sou do Rio de Janeiro.
A: Oh, eu amo o Rio. É minha cidade preferida.
B: De onde você é?
A: Sou de Nova Iorque. ${ }^{10}$

Porém, a interação se limita a isso. Nada mais sabemos sobre eles e sobre a situação da personagem Elena e sua viagem para os Estados Unidos - não sabemos se ela está indo como turista, a negócios, com pretensão de morar ou se já mora naquele país. Também não conhecemos suas expectativas sobre essa viagem. As personagens não formulam perguntas nesse sentido. Essas personagens poderiam ser de qualquer nacionalidade que não faria diferença para a composição do exercício. Aliás, poderíamos até mesmo trocar a língua (do inglês para o francês, por exemplo) que o diálogo poderia ser o mesmo, com as mesmas personagens. Acreditamos que isso se deve pela internacionalização deste LD que é usado em diferentes países do mundo. As situações

\footnotetext{
10 “A: Hi, I'm Mike. What's your name?

B: Oh, hello. I'm Elena.

A: Are you American?

B: No, I'm not. I'm Brazilian. I'm from Rio de Janeiro.

A: Oh, I Love Rio. It's my favorite city.

B: Where are you from?

A: I'm from New York.
} 
descritas, portanto, deveriam ser compreendidas por alunos representantes de culturas diversas.

1 Complete the questions and answers for the pictures $(a-f)$.
a) Is he Chinese?
Yes, he is.
b) Are ___ Spanish?
c) _t Japanese?
d) Russian?
Yes, they
Yes,
e) American?
f) British?
Yes,
Yes,
Yes,

21.07 Listen, check, and repeat
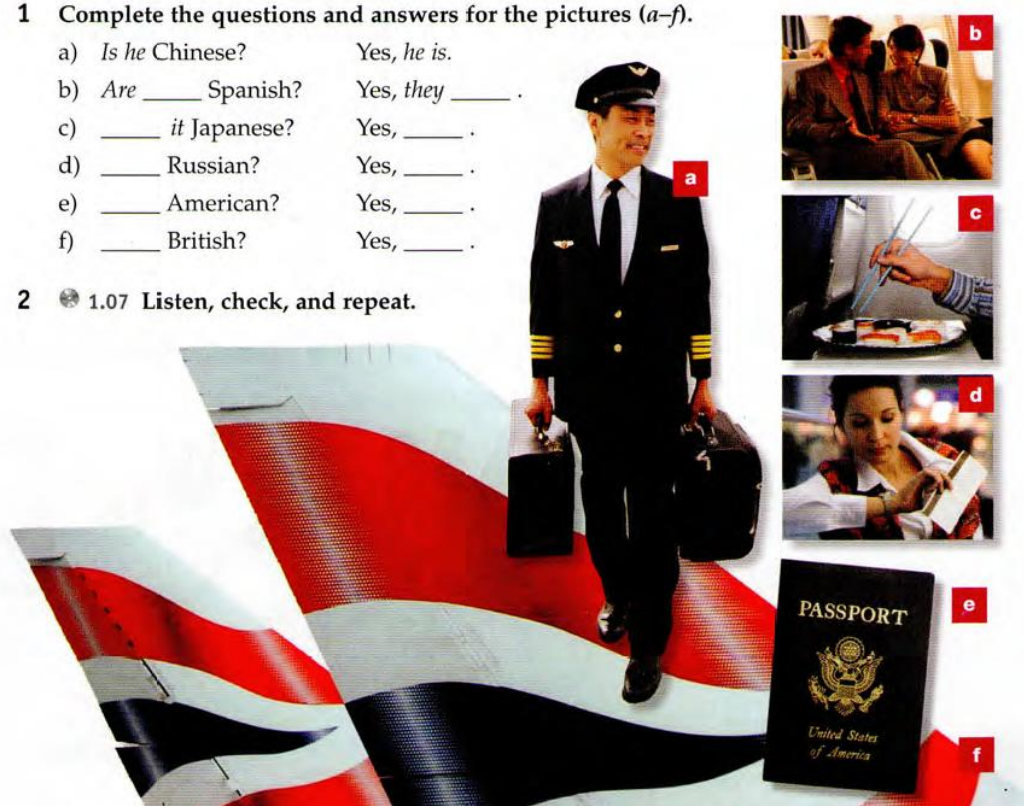

PASSPORT

Figura 2

Outro exemplo está na página seguinte desta mesma unidade, encontramos exemplos, com figuras, para a prática de perguntas com o verbo ser/estar ${ }^{11}$, na sessão "Grammar". No primeiro exemplo, encontramos a pergunta: "Ele é chinês?" com a resposta, já pronta, "sim, ele é"12 (ibid., p. 5). Mais uma figura com a pergunta "Eles são espanhóis?" e os alunos precisam completar afirmativamente "Sim, eles..."13. (ibid., p. 5) (figura 2). Essas personagens estão presentes nesta sessão com o objetivo de ilustrar as páginas do livro. Não temos acesso a informações sobre elas e o exercício é de substituição. Como colocado na apresentação do livro, os autores acreditam que drill $^{14}$ é uma forma pertinente de exercício e serve para praticar o uso de estruturas já prontas e dadas, em uma situação controlada. O exercício não possui conexão com algum ponto da

\footnotetext{
${ }^{11}$ To be.

${ }^{12}$ Is He Chinese?

Yes, He is.

${ }^{13}$ Are Spanish?

Yes, they

${ }^{14}$ Aqui se entende como Drill exercícios com diálogos já prontos, no quais os alunos precisam apenas trocar algumas palavras, que já são fornecidas. Cabe aos alunos apenas fazer essas trocas para praticar um diálogo já pronto.
} 
vida pessoal dos alunos ou com sua cultura, seja ela estadunidense ou estrangeira. Os alunos são tratados como repetidores de itens gramaticais.

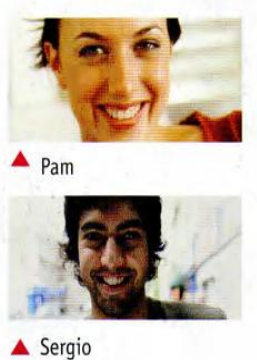

$\Delta$ Sergio
2 2.02 Listen to two interviews about water sports. Circle the time expressions you hear in each interview.

\begin{tabular}{l|l|l} 
& Pam & Sergio \\
\hline went swimming & a) in 2006/(in August & c) on Monday / yesterday \\
\hline went sailing & & d) a long time ago / three days ago \\
\hline went windsurfing & b) last week / last summer & \\
\hline went scuba diving & - & e) last year / last month
\end{tabular}

Figura 3

Um terceiro exemplo foi retirado da unidade 7 "Oceano", exemplo de personagem que não é estadunidense. Em um exercício de escuta, uma mulher está entrevistando pessoas para saber sobre a prática de esportes aquáticos (ibid., p. 44) (figura 3). Uma das entrevistas é feita com um rapaz cujo nome é Sérgio Fernandes Almira Oliveira. Assim que ele diz a ela o seu nome, a entrevistadora ri da resposta. Esse tipo de reação (rir de outra personagem desconhecida) não acontece nenhuma vez no NAIO entre personagens com indícios de serem estadunidense (nomes, características físicas, etc.).

Podemos considerar esse exemplo como uma representação da força centrífuga de Bakhtin $(2003)^{16}$. Sérgio não está sendo tratado com uma polidez extrema. Apesar de a entrevistadora rir de seu nome, Sérgio responde as perguntas como se nada tivesse acontecido, tranquilamente; o estranhamento da entrevistadora é aceito de modo positivo. O tipo de reação executado pela entrevistadora não é o que se espera encontrar em um exercício de escuta de LD. Geralmente o encontro entre personagens de diferentes origens é colocado através de muita educação e polidez. Neste exemplo encontramos o contrário: a personagem estrangeira não é tratada ${ }^{17}$ dessa forma tão cuidadosa, assim representando a presença da força centrífuga.

\footnotetext{
${ }^{15}$ Unit 7 Ocean.

${ }^{16}$ Como colocado em 1.3 Concepção de linguagem.

${ }^{17}$ Esse tratamento não é considerado negativo, apenas diferente de outros exemplos geralmente encontrados nos LD.
} 


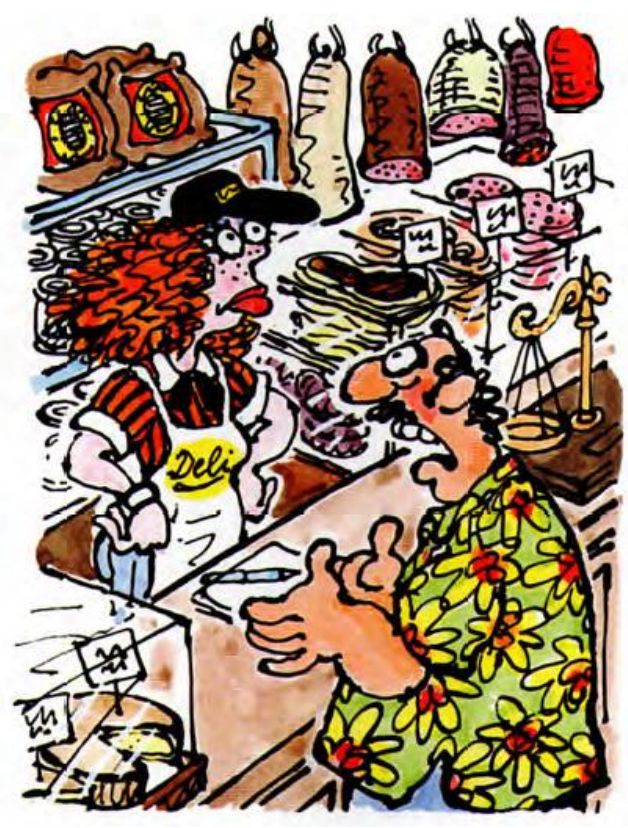

Figura 4

Por fim, a última atividade apresentada neste trabalho encontra-se na unidade 10 "Comida"18 , na sessão "Expressões úteis"19 (ibid., p. 70), encontramos um homem numa loja tentado comprar um sanduíche (figura 4). Como o exemplo é acompanhado de áudio, sabemos pela escuta que ele não possui um sotaque tipicamente de falante nativo e nem se aproxima a essa vertente, e com isso tem dificuldades em se expressar. Além disso, na figura ele está vestindo uma camisa florida, apresentando-se como uma imagem estereotipada de um turista. Como apontado anteriormente, na visão tradicional de cultura existe uma tendência a enxergar a cultura do outro a partir do estereótipo. Esta visão é limitadora, e universalmente reconhecida. A impaciência da atendente é claramente verificada no áudio porque podemos perceber pelo seu tom de voz que ela está irritada pelo desentendimento do cliente. No começo, a mulher não faz questão de ajudá-lo e fala rapidamente. Como o homem não a entende, ela começa a falar muito devagar, num tom que chega a ser cômico.

Assim como no exemplo anterior, temos uma reação que não se espera encontrar em um LD. Apesar de não sabermos informações pessoais e históricas de nenhuma das duas, sabemos que a personagem estrangeira é destratada pela personagem da loja. Como

\footnotetext{
${ }^{18}$ Unit 10 Food.

${ }^{19}$ Useful Phrases.
} 
no exemplo de Sérgio, apesar da rispidez por parte de um nativo, o turista continua se esforçando para fazer o pedido normalmente, como se nada tivesse acontecido. Mais uma vez, encontramos um exemplo da força centrífuga de Bakhtin (2003). Aqui os alunos têm contato com o que pode acontecer até mesmo com eles, se forem para um país cuja língua não dominem. Aliás, esta situação pode ocorrer até mesmo independentemente da língua. Não queremos aqui generalizar, mas sabemos que as pessoas nem sempre tratam a todos com extrema polidez e alegria como em outros exemplos encontrados em geral nos LDs.

Se pensarmos nas forças centrípetas de Bakhtin, poderíamos dizer que é esperado que os estrangeiros sejam bem tratados pelos nativos dos países falantes de inglês, que esse encontro entre diferentes culturas aconteça sem estranhamentos, um aceitando o outro apesar das diferenças. Assim sendo, os personagens, retirados do LD analisado, seriam um exemplo dessa força. Esse exemplo é predominante no livro, pois a maioria das personagens que aparecem em contato com culturas diferentes da sua aparece sendo extremamente educado.

O LD em questão não propõe nenhuma atividade que explore a questão da diferença e/ou possíveis reações dos próprios alunos, nem sequer faz alguma menção a qualquer particularidade nesse sentindo no livro do professor. Poderia ser uma possibilidade para chamar atenção dos alunos para a existência de diferentes discursos, diferentes comportamentos, diferentes possibilidades quando estamos em contato com outra cultura. Uma alternativa seria o professor perguntar a seus alunos o que eles acharam das reações das personagens, como eles acham que iriam reagir se estivessem em uma situação semelhante, se já estiveram na posição dos personagens.

Além disso, as personagens não representam uma cultura em si, em outras palavras, isto equivale dizer que as suas nacionalidades poderiam ser trocadas que isso não interferiria no objetivo de cada exercício ou nos exemplos do livro. Deste modo, a questão da cultura não é abordada de forma satisfatória pelo LD, pois pode existir uma simplificação de todas as cultuas, como se todas pudessem ocupar o lugar uma das outras sem nenhuma implicação. Deste modo, o aluno de línguas/ culturas estrangeiras precisa estar consciente de que o uso de uma língua não se resume em apenas fazer escolhas lexicais. Aprender uma língua estrangeira também implica em pensar em atitudes e comportamentos que podem ser diferentes do que estamos habituados. Como Janzen (2005) coloca, apenas aprender estruturas gramaticais não é suficiente para o aprendiz de 
uma língua ser proficiente, é preciso ir além, pensar essa cultura alvo para entender e se fazer ser entendido.

Para o aluno de língua estrangeira, é essencial que possa ter a oportunidade de pensar nas forças centrípetas e centrífugas que envolvem o aprendizado de uma língua. Uma das maneiras que essas forças aparecem é através do LD, que traz textos, informações sobre lugares e comportamentos. Se os livros apenas apresentam uma versão dessas forças, o pensar essas diferentes possibilidades ficam comprometido. O mesmo acontece se as diferentes forças do discurso são apresentadas, mas não sã problematizadas.

\section{CONSIDERAÇÕES FINAIS}

Podemos concluir que os alunos podem criar uma imagem que tenda à construção de estereótipos do país que serve como pano de fundo para as atividades de seus LDs a partir do que foi escolhido como representação da cultura de determinado país. As personagens e outras representações não contribuem para a formação de uma ideia de cultura pluralista, maleável e que esteja em constante mudança, pelo menos não com base no LD analisado brevemente neste estudo.

Assim, o conteúdo que aparece nos LDs não convida os alunos (nem os professores) a questionar as diversas relações entre culturas diferentes. O LD se torna o representante de uma força centrípeta, em que a cultura se apresenta sem conflitos e sem convites à reflexão, que poderiam proporcionar aos alunos um questionamento/posicionamento em relação às propostas/atividades sugeridas. Assim sendo, as forças centrífugas não são representadas no LD analisado e esta lacuna provoca a restrição da compreensão possível de uma dada cultura.

Cabe ao professor interferir e convidar o aluno a analisar as personagens apresentadas nos LDs e questionar as situações em que aparecem. O papel do professor não se restringe, como mencionado anteriormente, em utilizar o LD como único meio de estudo, mas a utilizá-lo como uma ferramenta de apoio. Assim, os professores podem procurar outros recursos para acrescentar aos conteúdos do LD e - assim - incorporar o universo cultural dos alunos no processo de ensino-aprendizagem da língua estrangeira. Da mesma forma, o docente pode adaptar o material que utiliza em suas aulas, verificar as 
exigências de seus alunos, o contexto de suas salas de aula e utilizar o LD da melhor forma possível para suas diferentes realidades.

Seria interessante verificar como isso acontece em sala de aula, com sujeitos reais. Poderíamos nos perguntar se o professor realmente segue a risca os materiais. Como os professores adaptam os LD para suas realidades e se com essas adaptações estão incluídas reflexões sobre o contato entre diferentes culturas e sobre uma visão intercultural sobre o aprender uma língua estrangeira.

\section{REFERÊNCIAS}

ALMEIDA, Mariza Riva de. Um olhar intercultural na formação de professores de língua estrangeiras. Curitiba: UFPR. Tese (Doutorado), 2011.

BAKHTIN, Mikhail. Estética da criação verbal. São Paulo: Martins Fontes, 2003. Hucitec, 2002.

Questões de literatura e de estética. A teoria do romance. São Paulo: . (VOLOCHÍNOV, V. N.). Marxismo e filosofia da linguagem. São Paulo: Editora Hucitec, 2009.

BATISTA, Antônio Augusto Gomes. "Um objeto variável e instável: textos, impressos e livros didáticos". IN: ABREU, Márcia (org). Leitura, História e História da Leitura. Coleção Histórias de Leitura, Campinas: Mercado de Letras/ Associação de Leitura do Brasil; São Paulo: FAPESP, $1^{\text {a }}$ re-impressão, 2002, p. 529-575.

BHABHA, Homi K. O Local da Cultura. Belo Horizonte: Ed. UFMG, 1998.

CARMAGNANI, Anna Maria G. "A concepção de professor e de aluno no livro didático e o ensino de redação em LM e LE”. IN: CORACINI, M. J. (org.) Interpretação, autoria e legitimação do livro didático. Campinas, SP: Pontes Editores, 2011.

CORACINI, Maria José. "O livro didático nos discursos da Linguística Aplicada e da sala de aula". IN: CORACINI, M. J. (org.) Interpretação, autoria e legitimação do livro didático. Campinas, SP: Pontes Editores, 2011.

EAGLETON, Terry. A ideia de cultura. São Paulo: editora Unesp, 2005.

FARACO, Carlos Alberto. Linguagem \& diálogo: as ideias linguíísticas do Círculo de Bakhtin. São Paulo: Parábola Editorial, 2009.

FREITAG, Bárbara; COSTA, Wanderly. F.; MOTTA, Valéria R. O livro didático em questão. São Paulo, Cortez, 1989. 
GRIGOLETTO, Marisa. "Leitura e funcionamento discursivo do Livro didático". IN: CORACINI, M. J. (org.) Interpretação, autoria e legitimação do livro didático. Campinas, SP: Pontes Editores, 2011.

JANZEN, Henrique. O Ateneu e Jakob Von Gunten: um diálogo intercultural possível. São Paulo, 2005. Tese (Doutorado), USP.

Concepções de cultura e o ensino de línguas estrangeiras modernas. IN SCHMIDT, M. A.; GARCIA, T. M. F. B.; HORN, G. B.(orgs.) Diálogos e perspectivas de investigação. Unijuí: Ijuí, 2008. p. 63-76.

MAIOR segmental do mercado editorial é o de livros didáticos. Época. Editora Globo: São Paulo, $\quad \mathrm{n}^{\mathrm{o}} \quad 492, \quad 2007 . \quad$ Disponível em: http://revistaepoca.globo.com/Revista/Epoca/1,,EDG79649-5856,00.html>. Acesso em: 25 abril 2013.

TEDESCHI, Losandro. Interculturalidade: a igualdade e a diferença em debate. IN:TEDESCHI, Losandro et al (orgs.) Abordagens interculturais. Porto Alegre: Martins Livreiro- editor, 2008.

\section{Obra analisada:}

JONES, Vaughan; KAY, Sue. New American Inside Out - student's book. Bangkok, Cidade do México: 2009. 